International session 2

\title{
UPDATED INFORMATIONS ON RHINOLOGY RESEARCH IN MALAYSIA
}

\author{
Salina Husain \\ Department of Otorhinolaryngology-Head and Neck Surgery, Faculty of Medicine, \\ Universiti Kebangsaan Malaysia Medical Centre, Kuala Lumpur, Malaysia
}

\begin{abstract}
Malaysia is committed to discovering and building knowledge for research. Various internal and external grants available to stimulate and encourage high caliber master students, PhD candidates, PhD graduates and academicians

to conduct, publish and present their new research findings.
\end{abstract} There has been a significant increase in the number of rhinology research in our country over the last few years. The aim of this presentation is to share an updated list of research in rhinology. 